Relations industrielles

Industrial Relations

\title{
Employment Policy and the Labor Market, edited by Arthur M. Ross, University of California Press, 1965, 406 pages.
}

\section{Claude-R. Têtu}

Volume 21, numéro 3, 1966

URI : https://id.erudit.org/iderudit/027713ar

DOI : https://doi.org/10.7202/027713ar

Aller au sommaire du numéro

Éditeur(s)

Département des relations industrielles de l'Université Laval

ISSN

0034-379X (imprimé)

1703-8138 (numérique)

Découvrir la revue

Citer ce compte rendu

Têtu, C.-R. (1966). Compte rendu de [Employment Policy and the Labor Market, edited by Arthur M. Ross, University of California Press, 1965, 406 pages.] Relations industrielles / Industrial Relations, 21(3), 464-464.

https://doi.org/10.7202/027713ar

Tous droits réservés (C Département des relations industrielles de l'Université Laval, 1966
Ce document est protégé par la loi sur le droit d'auteur. L'utilisation des services d'Érudit (y compris la reproduction) est assujettie à sa politique d'utilisation que vous pouvez consulter en ligne.

https://apropos.erudit.org/fr/usagers/politique-dutilisation/ 
ployées. Hays suggère de les laisser exclusivement à l'action volontaire des parties. Quont aux problèmes des pressions exercées sur les arbitres relativement à leur réengagement futur por les parties, l'auteur rejoint les partisans des tribunaux du travail.

\section{Emile VALLeE}

Employment Policy and the Labor Market, Edited by Arthur M. Ross, University of California Press, 1965, 406 pages

Cet ourrage traite d'un sujet dont l'incidence sur la vie économique de toute nation industrielle est primordiale. Le chômage permanent, aux Etats-Unis, exige l'élaboration de politiques nouvelles, tant publiques que privées. C'est pourquoi le thème général du volume est qu'une compréhension profonde de la situation résultera en des politiques d'action efficaces à l'échelle nationale.

Cette recherche de solutions nouvelles à un vieux problème s'accompagne d'une critique objective de la relation entre le plein emploi et les autres buts de la politique économique américaine. Parmi ces derniers, on trouve la croissance économique, la stabilité des prix, la restriction des salaires, la balance des paiements, la restriction des dépenses fédérales et un budget fédéral équilibré.

11 est utile de mentionner que ce livre consiste en quatorze communications qui furent présentées à la Conférence sur le chômage à Boulder, Colorado, entre le 15 et le 19 juin 1964. Cette conférence s'inscrit dans le cadre d'un programme de recherche sur le chômage conduit par: « The Institute of Industrial Relations, University of California, Berkeley $»$. La première partie du volume porte sur les politiques générales d'emploi et établit une relation entre le chômage et l'inflation. Le modèle de R.A. Gordon sur les relations entre les diverses politiques, de même que la théorie des politiques de salaires-prix présentée par Murray Edelman et Robben W. Fleming, sont des apports importants à l'étude du chômage.

La seconde partie traite des causes, des concepts et des mesures du chômage. Au point de départ, on étudie la participation de la force de travail à l'aide d'une analyse statistique qui nous est fournie par William $G$. Bowen et T.A. Finegan. Plusieurs recherches sur le chômage camouflé, sur l'emploi vacant, sur le chômage saisonnier et surtout structurel se regroupent ici.
La troisième section de ce volume envisage le marché du travail et les politiques de formation. On y retrouve une analyse des coûts et des bénéfices des programmes ce formation qui fut effectué par Gerald G. Somers, de même qu'un exposé substantiel sur l'apprentissage, sa nécessité et ses lacunes.

Enfin, ovec Paul Jacob on laisse le domaine théorique pour jeter un coup d'oeil sur les chômeurs eux-mêmes. II y parvint en les écoutant, en vivant avec eux et même en prétendant être un des leurs.

$\mathrm{Ce}$ volume nous livre les recherches les plus récentes dans le domaine complexe du marché du travail tant sur le plan de l'offre que sur celui de la demande. Les résultats de ces recherches jettent une lumière nouvelle sur le chômage que l'on considère comme le premier problème économique des Etats-Unis. II est évident que plusieurs des chapitres de ce volume seront cités et discutés dans les années à venir.

\section{Claude-R. TETU}

\section{L'Avenir professionnel des jeunes du milieu populaire, Pierre Idiart, Reine Goldstein, Collection « jeunesse actualité », Les Edi- tions Ouvrières, Paris, 1965. 205 pages.}

Cette étude fait partie d'une série d'enquêtes menées en France por la J.O.C. et la J.O.C.F. et dont le but était de mettre en lumière les multiples obstacles que rencontrent les jeunes du milieu populaire pour réussir leur vie ouvrière. $A$ la suite des 60,000 réponses fournies par les jeunes qui ont participé à l'enquête-référendum intitulée: «Stop à l'échec des jeunes ", les outeurs ont essayé de dégager les différents problèmes de l'orientation professionnelle, de la scolarisation, de l'apprentissage et de l'emploi des jeunes travailleurs.

Dans une première partie intitulée: «Stop à l'échec de quels jeunes?", les auteurs tentent de montrer les grands profils statistiques de la jeunesse ouvrière française. On étudie d'abord la proportion des jeunes par rapport à la population globale puis par rapport au milieu populaire; on essaie ensuite de voir comment se répartissent ces jeunes dans le milieu scolaire et le milieu du travail. Les auteurs traitent aussi des différentes situations conditionnant la vie de travail des jeunes: qualifications des jeunes travailleurs, répartition suivant ces qualifications ainsi que distribution des jeunes dans les entreprises. 